\title{
Das Lied vom Leben und Tod
}

\section{Erhard Taverna}

Dr. med., Mitglied der Redaktion

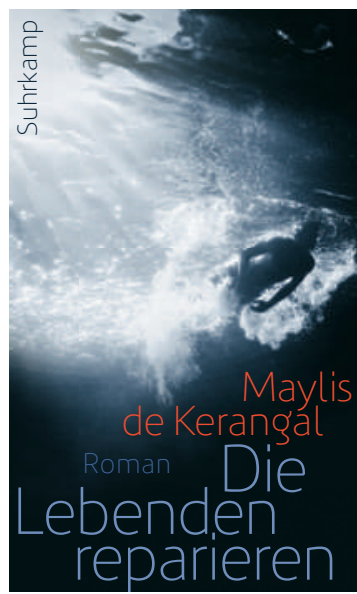

Maylis de Kerangal

Die Lebenden reparieren

Berlin: Suhrkamp; 2015.

255 Seiten. 28.50 CHF.

ISBN 978-3-518-42478-0

(Originalversion 2014:

Réparer les vivants*)

Zwar ist es kein Lied, sondern ein Roman, den die französische Autorin Maylis de Kerangal geschrieben hat. Ein Bericht aus dem Zwischenreich zwischen Hirntod und Herztod, wenn die zerebralen Funktionen, einschliesslich Hirnstamm, irreversibel ausgefallen sind, die übrigen Organe aber für eine Transplantation in Frage kommen.

\section{Was für die meisten abstrakt bleibt, gerät bei} Kerangal dank grossem, sprachlichem Können zu einem grausamen und zugleich lebensbejahenden Drama.

Kraftvoll, lyrisch und präzis protokolliert die Autorin die Ereignisse bis zur Organentnahme: den Unfalltod des 19-jährigen Surfers Simon Limbres, die Reaktionen der Eltern und aller Beteiligten, die der Reihe nach ihre Aufgabe zu erfüllen haben. Vom grossartig erzählten Wellenritt dreier junger Freunde, vom Autounfall auf der Rückreise, von der Notfallaufnahme und allen gesetzlich vorgeschriebenen Prozeduren. Ein dunkler, melodiöser Gesang, intensiv und schmerzhaft, minutiös in allen Details, bis in das Innenleben der Pflegenden und Ärzte. Eine Reportage über 24 Stunden. Über den Schock, das Gespräch mit den Angehörigen, die Entnahmeteams, die Verwalterin der Organdatenbank, die bürokratischen Rituale, Telefonate und Transporte bis zum letzten Akt im OP, wo ein singender Spitalangestellter den ausgeweideten Leichnam wäscht und ihm wieder eine Würde verleiht. Das Bestattungsritual für einen griechischen Helden: «Er versetzt ihn in einen postmortalen Raum, den der Tod nicht mehr erreicht, den Raum des unsterblichen Ruhms, der Legenden, des Gesangs und der Schrift.» Herz, Nieren und Leber finden ihren Weg in den Körper anderer Menschen.

Viele Details der rasanten Folge aufwühlender Szenen machen klar, wie Hirntod und Transplantationsmedizin miteinander verknüpft sind.

Die Grundlagen der Diagnostik sind in Frankreich nicht wesentlich anders als in der Schweiz geregelt. Hier ist es ein junger Mann, der vielleicht am Steuer einnickte, während hierzulande, gemäss Swisstransplant, der typische Spender mit 52 Jahren an einer schweren Hirnblutung stirbt. Der ehemalige Herzchirurg und Direktor Franz Immer plant, den bundesrätlichen Aktionsplan zur Erhöhung der Spenderrate umzusetzen. Kein leichtes Unterfangen, da die Schweiz im internationalen Vergleich schlecht wegkommt. Seit 2007 existiert eine zentrale Lösung mit nationalen Wartelisten und einem Gesetz, das die Voraussetzungen gemäss den Richtlinien von der Schweizerischen Akademie der Medizinischen Wissenschaften SAMW festlegt.

Maylis de Kerangal leistet mit ihrer virtuosen Sprache Entwicklungshilfe. Was für die meisten abstrakt bleibt, gerät bei ihr dank grossem, sprachlichem Können zu einem grausamen und zugleich lebensbejahenden Drama, das die Leserinnen und Leser, egal ob Laien oder Fachpersonen, mit allen eigenen Hoffnungen und Ängsten konfrontiert. Inwieweit der Nachweis des Hirntodes ein ebenso sicheres Todeszeichen wie der Herz- und Atemstillstand ist, wird oft angezweifelt.

\section{Ein dunkler, melodiöser Gesang, intensiv} und schmerzhaft, minutiös in allen Details.

Letztlich eine philosophische und spirituelle Frage nach dem Wesen des Todes überhaupt, die nicht allein medizinisch zu beantworten ist. Auch Maylis de Kerangal kann diese Frage nicht endgültig beantworten. Aber ihr literarisches Meisterwerk eröffnet Dimensionen, die vielleicht eine eigene Stellungnahme erleichtern. 